\title{
Financial Management Innovation Model under New Accounting System Environment
}

\author{
Qin Shanshan \\ Shaanxi Vocational and Technical College of Finance and Economics,
} Xianyang , Shanxi, 712000

\begin{abstract}
With the continuous progress of the market economy and the improvement of the economic system, the new accounting system appeared, which provides a comprehensive and systematic basis for the scientific management of enterprise finance. However, the financial management mode applied by the operating organizations can not adapt to the specific requirements under the macroenvironment, affecting the strategic objectives of the formulation and implementation. In this environment, the impact of the new accounting system in improving the financial management model and the existing problems of the current financial management model were described. The new accounting system in the financial management of innovation in the environment model was studied for all types of operating institutions to establish and improve financial management model to make recommendations to promote the operation of sustained and stable development.

Key words: market economy; new accounting system; financial management mode.
\end{abstract}

\section{Introduction:}

Since the world trade, market competition is increasingly fierce, the new accounting system within the financial management system has gradually been social and business attention. Sound and effective financial management model is an important part to promote the rapid economic upgrading and has has a particularly far-reaching impact on the comprehensive ability to enhance China's economic management. For the low and short limiting of Chinese new 
accounting system, there are a lot of problems to solve at present. In order to meet the requirements of the market economy system and to ensure that the enterprise foothold and develop in the market competition, the financial management system must be promptly applied to the financial management system.

\section{The Practical Significance of Implementing New Accounting System in Enterprises}

Corporate financial management reflects the strong specificity, and its management focus is on corporate assets. Under the new accounting system environment, enterprise financial management gradually systematic and standardized. Standardized management can not only increase the economic efficiency of enterprises, but also reduce financial risks, stabilize corporate finance, and ensure better development of enterprises. At the same time, the operation of the new accounting system can better support the national macrocontrol, can scientifically and properly handle the problems faced by enterprise financial management and enhance the quality of financial information and authenticity. Therefore, the implementation of the new accounting system, can effectively improve the financial management environment.

The important role of the new accounting system is to protect the public interests of the people. The current accounting environment includes political, legal, social, economic and other factors. The tax law is not only an important part of the accounting environment, but also the main basis for formulating the new accounting system. Tax is an important source of national income, while the state invested in social welfare funds are derived from tax revenue. Public interest capacity has a direct impact on the formulation and development of the accounting system. Only there is the sound national tax, can public welfare better enhance. Therefore, the introduction of the new accounting system, is a better way to safeguard the public interest and has important practical significance to promote the harmonious development of society.

According to the analysis we learned that the new accounting system has a direct impact on the financial information of enterprises, and its formulation and implementation can improve the financial management environment and financial work mode. Under normal circumstances, we analyze the financial information on the basis of understanding of corporate capital, finance, assets, operations and other aspects. Therefore, the financial information for business management is particularly important. In addition, it is necessary to enhance the authenticity and accuracy of financial information. Only accurate and true financial information can help enterprise managers to formulate the correct development plan in order to effectively reduce financial risks. Formulation and implementation of the new accounting system will also help enterprises to standardize financial management and enhance the authenticity and accuracy of financial information. 


\section{Problems in Financial Management Mode in New Accounting Setting Environment}

During the operation of the new accounting system, the financial management mode of the operation organization can be improved to a certain extent, but there are still problems of poor internal control capability. For example, some operators did not establish a systematic, comprehensive and scientific financial control system, did not timely adjust and improve the internal financial system, not fully implement the financial control norms. In addition, because business leaders have decided to staff salaries, personnel transfer and other rights, which reduce the the work efficiency and motivation of supervisor to work, leading to the implementation of accounting supervision is not effectively implemented but in the form of surface.

Although the current operating agencies will be based on their actual situation and select the decentralized management or centralized management model, there are financial allocation and leadership relationships and other issues of the two operating models. Some financial institutions of the superior or subordinate units are separated from the financial affairs of the main body, which has great influence on the systematization and integrity of the financial affairs of the organization, and can not guarantee the quality of the implementation. Some agencies appoint a few functional departments to manage the financial affairs completely, reducing the ability to control and manage financial matters. The lack of operating institutions and financial management mode caused by the poor quality of the operation of the weak, weakening the level of the use of accounting system, so that enterprises face greater financial risk.

The operation of the new accounting system requires enterprises to have higher financial management capabilities. However, some operating organizations are still building financial management teams with backward management methods and obsolete ideas. As a result, operating organizations do not attach importance to opportunity costs during their financial management. Marginal cost, risk value and time value will result in the lack of scientific and effective financial management. The financial staff of the operating organization can not fully enhance the value of the enterprise and can not meet the new accounting target, leading to the implementation of the new accounting system, such as the distribution of reports, financial reports and accounting information processing.

\section{The Strategy of Innovating the Financial Management Mode under the New Accounting System}

The lack of financial internal control of the operating organization is directly related to the lack of financial early-warning mechanism and the lack of clear management objectives. Therefore, the operating organization should constantly perfect the two aspects when selecting the financial management mode. First of 
all, according to the requirements of the new accounting system and the current market economic development, change the past "interests as the core" of the financial management objectives, to establish more suited to the requirements of the market economy, "comprehensive strategic development goals", through this method of financial. On the one hand, this method can help operators to better understand the role of new accounting system in promoting the development of financial management and actively integrate the resources according to the financial management objectives. On the other hand, this method can help operators to better understand the role of new accounting system in promoting the development of financial management, to provide internal operations for the relevant basis to enhance the relevance and effectiveness of internal control and better achieve financial management objectives.

Secondly, the operating agencies should be aware of the financial management of the many vicious incidents are dealt with afterwards, so that enterprises suffer huge economic losses. Therefore, the development of internal control mechanisms should pay attention to the construction of a sound early warning mechanism to strength the ability of financial management and internal control. In the construction of early warning mechanism, enterprises should understand the role of internal audit system, according to their specific circumstances, and gradually to improve and perfect the internal audit system, and to constantly enhance the effectiveness of internal supervision, to improve financial management and the financial management mode of the operating environment, which has an unusual practical significance. In addition, operators should pay attention to the construction of information technology and standardized management system, facing the problem of internal information, it is necessary to gradually establish a sound network information system to ensure that enterprises can better manage the financial means through the network to carry out financial supervision and management.

The enterprise chooses scientific and normative financial management mode to avoid the financial risk to the maximum extent. It can fully evaluate and calculate the investment-related capital problem before expanding the new field and building the new project. It can effectively increase the resource utilization rate and reduce the investment risk, so the enterprise to establish a unified and scientific operating mechanism is to improve the effective management of financial strategy.

First of all, the operating agencies in accordance with the revenue of the financial items, expenditure projects, can build accurate, clear, specific breakdown, and develop targeted, standardized and strong management, which is to improve the operational monitoring and management of funds flow trends are particularly important of the value of enterprises to enhance and improve the operating mechanism to provide reference data. Second, the performance of financial management model in the operation of the budget is a good way for financial management practices with management objectives to improve the relationship between the interests of the relationship between distribution and business leaders to play an active role. Finally, the operating agencies should be aware of the new accounting system in promoting and safeguarding the 
functioning of institutions, and in accordance with the actual needs of the financial long-term strategy, the current profit margins and long-term development planning, responsibility and management objectives clearly defined, the enterprise to properly handle the relationship between the upper and lower levels and the development of various stages of the development of a guiding role, with the various departments in the organization of financial management to arrange for special managers and responsible for the different departments of the quality of financial management standards and improve the more obvious effect.

At the same time, there is a lack of communication and coordination among various levels of financial management within the organization, and there is a lack of perfect operating mechanism. The relationship between the various levels and departments is not close to the establishment of a sound communication platform. In the choice of financial management mode, building the information network and operation system, laying the conditions and providing basis for the unified financial management mode of the operating organization, effectively solving the problem of non-uniform financial management and decentralization of rights have an important role in reducing operational risks, reducing operating costs and increasing operating profits.

At present, there are good and bad aspects of professional ethics, the ability to deal with accounting practice, the level of professional knowledge of China's accounting staff. It is necessary to strengthen the operating institutions to run the new accounting system, to gradually enhance the professional quality and overall quality of corporate finance, to use the following strategy. First, the operating accounting personnel, it should have the accounting qualification certificate as the basis for hiring to ensure that financial management personnel with sufficient knowledge of accounting to meet the specific requirements of financial management, which is important for the for the reduction when operating organization to train the cost of financial management personnel and to enhance the professional and stability of financial management personnel. This process should try to put an end to the "random arrangements for staff stoppage candidates," the undesirable phenomenon, otherwise it will hinder the reform and improvement of financial management, financial staff will be a serious blow to the initiative and enthusiasm.

Second, the operating institutions implement the post financial management personnel professional, systematic training to help them understand the new accounting system, and conscious self-optimization, not only with the new accounting system of financial skills and financial knowledge, but also based on market changes and new accounting system, the financial management of innovation and improvement of scientific guidance. For example, to optimize the financial staff currently used in accounting and financial management methods, so that they are more in line with the accounting method of the new accounting system requirements. At the same time, at present, under the era of large data, it is necessary to continuously enhance the capacity of accounting information, financial management personnel in enhancing the cultural quality and overall quality, so financial staff should pay attention to the application of computer and financial software capabilities, which can effectively enhance the accuracy and 
overall efficiency of financial management, and the workload and working pressure of financial management personnel can also further promote the standardization and standardization of financial management mode. Therefore, it is necessary to pay attention to each operation organization.

\section{Conclusion:}

With the reform of the market economy and the development of the commodity economy, the modern management of the role of the operating agencies have been unanimously approved, so the system of the new accounting system for the reform of financial management mode of operation to provide the basic system of protection. But in the process of gradual advantage, there are still many problems. Research and analysis of the new accounting system in the choice of financial management mode, in essence, is to reduce the adverse effects of the new accounting system, to enable operators to actively adapt to changes in the market economy and the development of an effective way. Therefore, we should pay attention to the internal control mode of financial management, to strengthen the supervision and management, to establish a scientific and systematic financial management mechanism, to enhance the professional quality and overall quality of financial management personnel to adjust and to perfect the financial management mode to promote the stability of operating institutions and sustainable development.

\section{References:}

[1] Fei Teng. New Accounting System under the Financial Management Model [J]. China Business Review, 2015,28: 64-66.

[2] Zhuang Qiaoping. Study on the Innovation of Financial Management Mode under the New Accounting System [J] .Management Manager, 2015,34: 156.

[3] Ma Jizhou.New accounting system under the financial management model [J]. Enterprise Technology Development, 2016, 05: 132-133 +135.

[4] Liu Wanqiu. New Accounting System under the Financial Management Model [J]. Management, 2016,27: 185.

[5] Sun Dilin. On the New Accounting System under the Financial Management Model [J]. Time Finance, 2015,05: 219 +221. 